\title{
Impact of disease duration on functional status of patients with spinocerebellar ataxia type 2
}

\author{
Repercussões do tempo de evolução sobre o perfil funcional de pacientes com ataxia \\ espinocerebelar do tipo 2
}

Thiago R. Padilha Amarante', Sibele Y. M. Takeda², Hélio A. G. Teive ${ }^{3,4}$, Marise Bueno Zonta ${ }^{1}$

\begin{abstract}
Objective: To correlate disease duration in spinocerebellar ataxia type 2 (SCA2) with disease severity, balance and functionality. Method: Sixteen SCA2 patients were analyzed for: disease duration, disease severity (SARA score), balance (Berg balance scale score) and functionality (FIM and Lawton scores). Results: Greater severity was correlated with worse functionality (Lawton: $r=-0.0561$, FIM: $r=-0.6402)$ and balance $(r=-0.7188)$. Longer disease duration was correlated with greater severity $(p=0.0002)$ and reduced functionality (FIM: $p=0.005$; Lawton: $p=0.0402)$ and balance $(p=0.0036)$. A year increase in disease duration corresponded to a 0.8 -point increase on the SARA scale, a 1.38-point decrease in FIM score, a 2.30-point decrease on the Berg balance scale and a 0.45-point decrease on the Lawton scale. Conclusion: Longer disease duration in this series of SCA2 patients was correlated with greater disease severity, worse balance and greater functional dependency.
\end{abstract}

Keywords: spinocerebellar ataxias; severity of illness index; postural balance.

RESUMO

Objetivo: Correlacionar com o tempo de evolução da doença em pacientes com ataxia espinocerebelar do tipo 2 (SCA2) com a gravidade, equilíbrio e funcionalidade. Método: Foram considerados dados de 16 indivíduos: tempo de evolução, nível de gravidade (SARA) e escores de equilíbrio (BERG) e funcionalidade (MIF e LAWTON). Resultados: A maior gravidade esteve relacionada aos piores escores de funcionalidade (LAWTON: $r=-0,0561$, MIF: $r=-0,6402)$ e de equilíbrio ( $r=-0,7188)$. O maior tempo de evolução esteve relacionado à maior gravidade ( $p=0,0002)$ e menor funcionalidade (MIF: $p=0,005$; Lawton ( $p=0,0402)$ e equilíbrio $(p=0,0036)$ sendo que para o aumento de um ano no tempo de evolução, espera-se um aumento de 0,8 pontos no escore da SARA, e decréscimo de 1,38 pontos na MIF, 2,30, na Berg e 0,45 na Lawton. Conclusão: 0 tempo de evolução dos sintomas está associado a maior gravidade da doença, pior equilíbrio e maior dependência funcional em pacientes comSCA2.

Palavras-chave: ataxia espinocerebelar; índice de gravidade da doença; equilíbrio postural.

Spinocerebellar ataxias (SCAs) are a large, complex group of neurodegenerative diseases characterized by progressive cerebellar ataxia with oculomotor abnormalities, dysarthria, pyramidal and extrapyramidal signs, pigmentary retinopathy, peripheral neuropathy and cognitive dysfunction, among other manifestations ${ }^{1,2}$. More than 40 types of SCA have been identified to date, including SCA type 2 (SCA2), which is caused by a CAG trinucleotide repeat expansion on chromosome 12q23-24.1.

The third most common form of SCA in Brazil is SCA2. Symptoms typically begin in the third decade of life and are associated with worse disease prognosis when they appear early ${ }^{1}$.
Clinical manifestations of the disease include action and rest tremor, polyneuropathy, upper motor neuron impairment and parkinsonism, which may predominate in some cases $^{3}$. A balance deficit is one of the most characteristic signs of SCA and one of the main factors directly affecting posture and functionality ${ }_{4}$. Increased disease severity implies greater impairment of postural balance and functionality, and increased risk of falls ${ }^{4,5}$.

An annual increase in the Scale for the Assessment and Rating of Ataxia (SARA) score of between 1.40 and 1.49 has been reported in patients with $\mathrm{SCA} 2^{6,7}$, but progression

${ }^{1}$ Universidade Federal do Paraná, Programa de Residência Integrada Multiprofissional em Cuidados Hospitalares - Saúde para Adultos e Idosos, Curitiba PR, Brasil; ${ }^{2}$ Universidade Federal do Paraná, Departamento de Prevenção e Reabilitação de Fisioterapia, Curitiba PR, Brasil;

${ }^{3}$ Universidade Federal do Paraná, Hospital de Clínicas, Departamento de Medicina Interna, Curitiba PR, Brasil;

${ }^{4}$ Universidade Federal do Paraná, Unidade dos Distúrbios do Movimento, Curitiba PR, Brasil.

Correspondence: Thiago R. Padilha Amarante; Av. Marechal Floriano Peixoto, 630 /11; 80010-130 Curitiba PR, Brasil; Email: thiagopadilha_10@hotmail.com Conflict of interest: There is no conflict of interest to declare.

Received 24 March 2017; Received in final form 01 August 2017; Accepted 04 August 2017. 
of functional loss and loss of balance have not yet been extensively described.

The aim of this study was, therefore, to assess functionality and balance in individuals with SCA2 and to correlate these with disease severity and duration.

\section{METHODS}

This was a retrospective, descriptive, cross-sectional study and was approved by the Committee for Ethics in Research at the Hospital de Clínicas, Federal University of Paraná (HC-UFPR) (CAAE: 48399915.7.0000.0096, ref. no.: 1.280.919).

The study sample was non-probabilistic and comprised men and women who were being followed up at the ataxia outpatient unit in the movement disorders unit at the Hospital de Clínicas, Federal University of Paraná.

Inclusion criteria were: being at least 18 years old; having a clinical diagnosis of SCA2; having a positive genetic test for SCA2 or having a family member who had a positive genetic test for SCA2; and taking coenzyme Q10 (100-500 mg/day) regularly. Individuals who had any musculoskeletal disorders that could affect their balance or functionality or who had other concomitant neurological disease (non-ataxic manifestations) were excluded.

Sixteen patients who had been diagnosed with SCA2 and had complete medical records were included in the study.

The following information was collected: age, gender, diagnosis, age of onset of ataxic symptoms, disease duration, disease severity, balance and functional-independence scores, and number of CAG repeats.

Balance was assessed on the Berg balance scale, which has 14 items and a maximum score of 56 . Scores of less than 46 indicate a high risk for falls ${ }^{8}$

Functional independence was assessed using the Functional Independence Measure (FIM), which assesses motor and cognitive domains. Scores vary from 18 to 126, and a high score indicates good functional independence.

The FIM measures disability in patients with functional limitations due to various causes and quantifies their need for assistance when performing motor and cognitive tasks associated with activities of daily living. The validated Brazilian version was published in 2004. The instrument is used in interviews with the patient and/or the patient's care-giver. In this study, it was only used with the patient ${ }^{9}$.

Independence for instrumental activities of daily living was assessed on the Lawton scale ${ }^{10}$, which consists of seven items and has a total score ranging from 7 (dependence on others to help carry out activities) to 21 (complete independence). The Lawton scale is an appropriate instrument to assess abilities that are considered more complex than the basic activities of daily living, such as shopping, doing housework and using transportation, and is useful for identifying a person's functional ability at a given time and how this improves or deteriorates over time ${ }^{11}$. The severity of ataxia was assessed on the SARA scale.

All the scales used in this study were translated into Portuguese and validated for Brazil ${ }^{12,13,14,15}$.

\section{Statistical analysis}

The descriptive analysis was based on the mean and standard deviation of the scores for severity, balance, instrumental activities of daily living and functionality. Correlations between parametric data were investigated using the Pearson correlation coefficient and Biostat ${ }^{\circ} 5.0$ for Windows. The Shapiro-Wilk test was used to test for normality. Analysis of variance, applied to regression, was used to test for a relationship between disease duration and severity, functionality and balance.

The scale of magnitudes for effect statistics proposed by Hopkins was used to interpret the correlation coefficients: $<0.1=$ trivial; 0.1 to $0.29=$ small; 0.30 to $0.49=$ moderate; 0.50 to $0.69=$ large; 0.70 to $0.90=$ very large; $>0.90=$ nearly perfect. A level of significance of $p<0.05$ was used.

\section{RESULTS}

Of the 16 patients evaluated, $75 \%(\mathrm{n}=12)$ were male. Mean age was $45.43 \pm 10.41$ years, and mean age at onset of symptoms was $35 \pm 8.72$ years. Mean disease duration was $9.12 \pm 4.61$ years, mean disease severity (SARA score) $11.4 \pm 4.65$, mean balance score on the Berg scale $37.25 \pm 15.61$, mean FIM score $115.37 \pm 9.64$ and mean score on the Lawton scale $17.25 \pm 4.09$. Disease duration, SARA, Lawton, FIM and Berg scores and number of CAG repeats for each patient are shown in Table 1.

There was a strong negative correlation between scores on the SARA and Lawton scales $(r=-0.0561)$, a strong negative correlation between SARA scores and FIM scores $(r=-0.6402)$, a strong negative correlation between SARA scores and Berg scores $(r=-0.7188)$, a strong positive correlation between Lawton scores and FIM scores $(\mathrm{r}=0.8963)$, a strong negative correlation between Lawton scores and Berg scores $(r=-0.8340)$ and an almost perfect correlation between FIM scores and Berg scores $(r=0.9674)$. The results of the correlation tests between the SARA, Berg, FIM and Lawton scores are shown in Table 2.

Linear regression revealed a significant relationship between disease duration and the SARA score $(p=0.0002)$, FIM score $(p=0.0051)$, Berg balance score $(p=0.0036)$ and Lawton score $(p=0.0402)$. These results are shown in the Figure and interpreted in Table 3.

\section{DISCUSSION}

This study of 16 SCA2 patients revealed significantly impaired functionality and balance. Disease severity was correlated with worse functionality and balance scores, and 
Table 1. Disease duration and functional independence, disease severity and balance scores for each patients.

\begin{tabular}{|c|c|c|c|c|c|c|c|c|}
\hline Patient & Gender & Current age & $\begin{array}{c}\text { Disease duration } \\
\text { (years) }\end{array}$ & SARA & Lawton & FIM & Berg & CAG repeats \\
\hline 1 & $\mathrm{~F}$ & 36 & 2 & 4.5 & 21 & 125 & 54 & $22 / 52$ \\
\hline 2 & M & 30 & 3 & 9 & 21 & 124 & 48 & $20 / 39$ \\
\hline 3 & M & 36 & 3 & 3 & 21 & 126 & 56 & - \\
\hline 4 & $\mathrm{~F}$ & 46 & 4 & 9 & 21 & 123 & 54 & $21 / 38$ \\
\hline 5 & M & 46 & 5 & 10 & 18 & 121 & 47 & $16 / 48$ \\
\hline 6 & M & 45 & 8 & 7 & 9 & 108 & 32 & $22 / 40$ \\
\hline 7 & M & 65 & 10 & 7.5 & 21 & 118 & 47 & $23 / 54$ \\
\hline 8 & M & 40 & 10 & 12 & 21 & 122 & 47 & $20 / 48$ \\
\hline 9 & M & 40 & 10 & 13 & 14 & 104 & 16 & $22 / 58$ \\
\hline 10 & M & 54 & 11 & 13 & 15 & 109 & 32 & $22 / 48$ \\
\hline 11 & M & 49 & 11 & 12.5 & 21 & 126 & 46 & - \\
\hline 12 & M & 44 & 11 & 18 & 17 & 118 & 23 & $20 / 37$ \\
\hline 13 & M & 42 & 12 & 12.5 & 17 & 115 & 40 & $20 / 46$ \\
\hline 14 & $\mathrm{~F}$ & 55 & 13 & 18.5 & 11 & 100 & 9 & $22 / 37$ \\
\hline 15 & $M$ & 33 & 15 & 18 & 12 & 96 & 5 & - \\
\hline 16 & $\mathrm{~F}$ & 66 & 18 & 15 & 16 & 111 & 28 & $22 / 56$ \\
\hline
\end{tabular}

F: female; M: male; SARA: total SARA (Scale for the Assessment and Rating of Ataxia; FIM: Functional Independence Measure) score; Berg: total score on the Berg scale; FIM: total score on the Functional Independence Measure scale; Lawton: total score on the Lawton independence for instrumental activities of daily living (ADL) scale.

Table 2. Correlation between SARA, Berg, FIM and Lawton scores, $p>0.05^{*}$

\begin{tabular}{lcccc}
\hline Variable & SARA & Berg & FIM & Lawton \\
\hline SARA & 1 & & \\
Berg & $(r)=-0.7188^{*}$ & 1 & \\
& $(p)=0.0017$ & & \\
FIM & $(r)=-0.6402^{*}$ & $(r)=0.9674^{*}$ & 1 \\
& $(p)=0.0075$ & $(p)=<0.0001$ & \\
Lawton & $(r)=-0.5061^{*}$ & $(r)=-0.8340 *$ & $(r)=-0.8963^{*}$ & 1 \\
& $(p)=0.0454$ & $(p)=<0.0001$ & $(p)=<0.0001$ & \\
\hline
\end{tabular}

SARA: Scale for the Assessment and Rating of Ataxia; FIM: Functional Independence Measure

greater disease duration was correlated with greater severity, worse balance and greater functional impairment.

Mean age at onset of symptoms in the study series was 35 years, in agreement with the literature, in which the age of onset is reported to be between the third and fifth decades of life $^{16}$. The main symptoms of ataxia are a balance deficit and worsening gait. The disease initially affects the legs, but as it progresses the symptoms extend to the trunk and $\mathrm{arms}^{2}$.

The mean Berg score was $37.25 \pm 15.61$, and minimum and maximum scores were 5 and 56 . The Berg test is objective and can identify an increased propensity for falls. Although a lower score on this scale is associated with a greater risk of falls, the relationship is not linear: between 56 and 54, a one-point decrease on the Berg scale is associated with a $3 \%$ to $4 \%$ increase in the risk of falls, but between 54 and 46 , a one-point decrease on the scale is associated with a $6 \%$ to $8 \%$ increase. Below 36 there is an almost $100 \%$ risk of falls. Hence, changes in the Berg score can lead to very different forecasts for the probability of falls ${ }^{8}$. It is reasonable to conclude, therefore, that the risk of falls for the patients in this study is close to $100 \%$.

The cerebellum plays a crucial role in the control of movement, locomotion and postural stability. Cerebellar degeneration in individuals with SCA2 can therefore affect postural control. It has also been suggested that postural instability is one of the main signs of SCA2 and leads to balance deficits and, consequently, limitations on the individual's ability to perform activities of daily living ${ }^{17}$.

The ability to maintain balance is an integral part of gross motor skills, and poor balance and inadequate posture result in difficulties performing activities of daily living ${ }^{18}$. In this series, the main functional difficulties involved locomotion (walking, moving around in a wheel chair and going up and down stairs). The implications for mobility are profound: more than $50 \%$ of patients with inherited neurological diseases report having incurred injuries as a result of falls, leading to morbidity and reduced quality of life. In addition, repeated falls instill intense fear of falling, so that patients restrict their activities and become less independent, limiting their ability to perform physical activities, which in turn affects their posture and gait control ${ }^{19}$.

In a study that assessed balance and functionality in 44 patients with SCA, Aizawa et $a .^{20}$ concluded that individuals with SCA have significant balance impairment and an increased risk of falls and that this affects their ability to perform certain activities, such as self-care, transfers, locomotion and instrumental activities of daily living. They also concluded that the more severe the ataxia, the greater the balance and functional impairment, corroborating the results of the present study.

Torrani et al. ${ }^{21}$,in a study that investigated whether there was a correlation between functional independence and balance in 

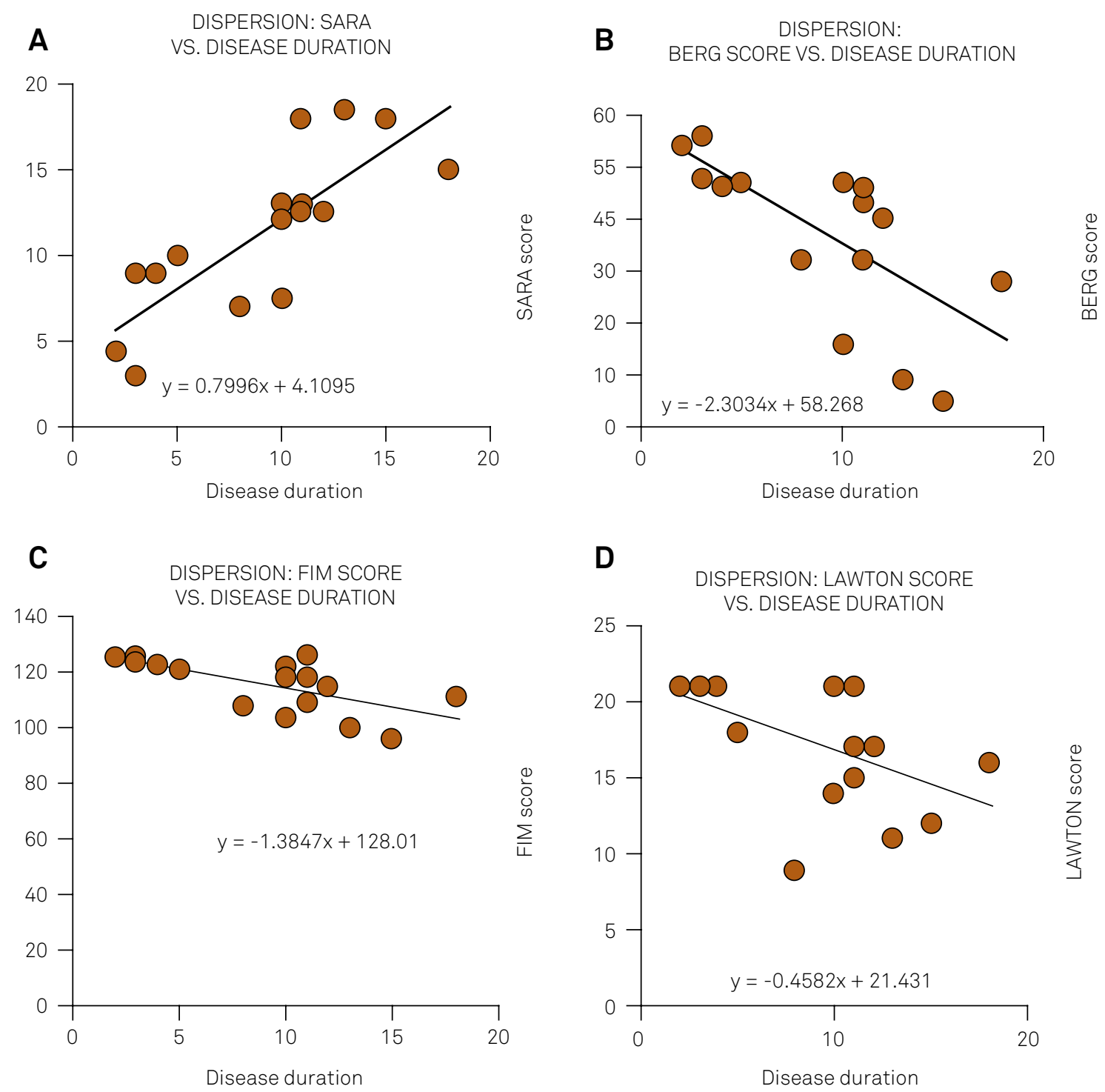

SARA: Scale for the Assessment and Rating of Ataxia; FIM: Functional Independence Measure

Figure. Relationship between disease duration and (A) disease severity (SARA), (B) balance (Berg) and (C) functionality (FIM and Lawton).

Table 3. Interpretation of the results of the linear regression analysis.

\begin{tabular}{lc} 
Variable & \multicolumn{1}{c}{ Interpretation } \\
\hline Disease duration vs. SARA & A 0.7996-point increase in SARA score can be expected for a year increase in disease duration \\
Disease duration vs. FIM & A 1.38-point decrease in FIM score can be expected for a year increase in disease duration \\
Disease duration vs. Berg & A 2.3034-point decrease in Berg score can be expected for a year increase in disease duration \\
Disease duration vs. Lawton & A 0.4582-point decrease in Lawton score can be expected for a year increase in disease duration \\
\hline SARA: Scale for the Assessment and Rating of Ataxia; FIM: Functional Independence Measure.
\end{tabular}

patients with SCA, concluded that the correlation between functional performance and balance was significant. They found that the greater the score on the Berg scale, the greater the FIM score. Again, their findings corroborate the results of this study.

The relationship between the scores on the FIM and Lawton scales shows clearly that a change in an individual's functionality directly affects his ability to perform instrumental activities of daily living, reflecting the major impact that certain diseases can have on patients' lives. Independence in basic activities of daily living, such as self-care and transferring, as well as in more complex, or instrumental, activities, such as preparing meals and using transportation, are important markers of functionality. Functionality, in turn, is dependent on balance, which was assessed here with the BERG balance scale. The instruments for assessing functional ability and balance used in this study not only allow the patient's need for 
care and his/her degree of independence to be quantified, but also can be markers of disease progression over time, as observed here. The cross-sectional nature of this study can be considered a limitation, as longitudinal analyses with these instruments could provide information on progression of functional disability in individual tasks. ${ }^{22}$

LeónCarrión et al. ${ }^{23}$, in a study involving patients with neurological sequelae following traumatic brain injury, reported a reduction in incapacity after an intensive multidisciplinary therapy program. They observed improvements of over $70 \%$ in functional, cognitive, emotional and behavioral deficits.

In a study by Lana et al. ${ }^{24}$ of patients with Parkinson's disease, dimensions related to physical aspects of the disease adversely affected patients' quality of life and limited their activities. As quality of life was not assessed in the present study, further studies focusing on this issue in patients with SCA should be carried out.

Multicenter studies with a greater number of subjects diagnosed with SCA2 should also be carried out, as well as studies using other instruments to assess functionality in these patients and the repercussions of non-cerebellar manifestations, such as spasticity, neuropathy and extrapyramidal signs, on functionality and balance.

In conclusion, disease duration in this series of SCA2 patients was correlated with greater disease severity, worse balance and greater functional dependency.

\section{References}

1. Teive HAG, Ashizawa T. Primary and secondary ataxias. Curr Opin Neurol. 2015;28(4):413-22. https://doi.org/10.1097/WC0.0000000000000227

2. Sun YM, Lu C, Wu ZY. Spinocerebellar ataxia: relationship between phenotype and genotype: a review. Clin Genet. 2016;90(4):305-14. https://doi.org/10.1111/cge.12808

3. Magaña JJ, Velázquez-Pérez L, Cisneros B. Spinocerebellar ataxia type 2: clinical presentation, molecular mechanisms, and therapeutic perspectives. Mol Neurobiol. 2013;47(1):90-104. https://doi.org/10.1007/s12035-012-8348-8

4. Luo L, Wang J, Raymond YL, Figueroa KP, Pulst SM, Kuo PH et al. The initial symptom and motor progression in spinocerebellar ataxias. Cerebellum. 2017;16(3):615-22. https://doi.org/10.1007/s12311-016-0836-3

5. Araujo MJL, Cardoso PL, Silva LC, Oliveira DA. A atuação da fisioterapia neurofuncional na doença de José-Machado: relato de caso. Neurobiologia. 2010;73(1):75-83.

6. Jacobi H, Montcel ST, Bauer P, Giunti P, Cook A, Labrum R et al. Long-term disease progression in spinocerebellar ataxia types 1, 2, 3 , and 6: a longitudinal cohort study. Lancet Neurol. 2015;14(11):1101-8. https://doi.org/10.1016/S1474-4422(15)00202-1

7. Lee YC, Liao YC, Wang PS, Lee IH, Lin KP, Soong BW. Comparison of cerebellar ataxias: a three-year prospective longitudinal assessment. Mov Disord. 2011;26(11):2081-7. https://doi.org/10.1002/mds.23809

8. Berg KO, Wood-Dauphinee SL, Williams JI, Maki BE. Measuring balance in the elderly: validation of an instrument. Can J Public Health. 1992;83 Suppl2:S7-1.

9. Assis CS, Batista LC, Wolosker N, Zerati AE, Gengo RC. Functional independence measure in patients with intermittent claudication. Rev Esc Enferm USP. 2015;49(5):756-61. http://dx.doi.org/10.1590/S0080-623420150000500007

10. Lawton MP, Brody EM. Assesment of older people: self-maintaining and instrumental activities of daily living. Gerontologist. 1969;9(3):179-86. https://doi.org/10.1093/geront/9.3_Part_1.179

11. FhonJR, Diniz MA, Leonardo KC, Kusumota L, Haas VJ, Partezani RA. Frailty syndrome related to disability in the elderly. Acta Paul Enferm. 2012;25(4):589-94. http://dx.doi.org/10.1590/S0103-21002012005000016

12. Riberto M, Miyazaki MH, Jucá SSH, Sakamoto H, Pinto PPN, Battistella LR. Validação da versão brasileira da Medida de Independência Funcional. Acta Fisiatr. 2004;11(2):72-6. http://dx.doi.org/10.5935/0104-7795.20040003

13. Miyamoto ST, Lombardi J, Berg KO, Ramos LR, Natour J. Brazilian version of the Berg balance scale. Braz J Med Biol Res 2004;37(9):1411-21. https://doi.org/10.1590/S0100-879X2004000900017
14. Santos RL, Junior JS. [Reliability of the Brazilian version of the Scale of Instrumental Activities of Daily Living[. RBPS. 2008;21(4):290-6. Portuguese. https://doi.org/10.5020/18061230.2008.p290

15. Braga Neto P, Godeiro Junior C, Dutra LA, Pedroso JL, Barsottini OGP. Translation and validation into Brazilian version of the Scale of the Assessment and Rating of Ataxia (SARA). Arq Neuropsiquiatr. 2010;68(2):228-30. https://doi.org/10.1590/S0004-282X2010000200014

16. Weyer A, Abele M, Schmitz-Hübsch T, Schoch B, Frings M, Timmann $D$ et al. Reliability and validity of the scale for the assessment and rating of ataxia: a study in 64 ataxia patients. Mov Disord. 2007(22):1633-7. https://doi.org/10.1002/mds.21544

17. Velázquez-Pérez L, Rodríguez-Labrada R, García-Rodríguez JC, Almaguer-Mederos LE, Cruz-Mariño T, Laffita-Mesa JM. A comprehensive review of Spinocerebellar ataxia type 2 in Cuba. Cerebellum. 2011;10(2):184-98. https://doi.org/10.1007/s12311-011-0265-2

18. Leonardi MM, Lopes GJ, Bezerra PP, Borges AP. [Impact of static and dynamic imbalance in the risk of falls in paients with spinocerebellar ataxia]. Rev Neurocienc. 2008:17(2):178-82. Portuguese.

19. Kembhavi G, Darrah J, Magill-Evans J, Loomis J. Using the berg balance scale to distinguish balance abilities in children with cerebral palsy. Pediatr Phys Ther. 2002;14(2):92-9. https://doi.org/10.1097/00001577-200214020-00005

20. Aizawa CY, Pedroso JL, Braga Neto P, Callegari MR, Barsottini OG. Patients with autosomal dominant spinocerebellar ataxia have more risk of falls, important balance impairment, and decreased ability to function. Arq Neuropsiquiatr 2013;71(8):508-11. https://doi.org/10.1590/0004-282X20130094

21. Torriani C, Mota EPO, Gomes CS, Batista C, Costa MC, Vieira EM et al. Avaliação comparativa do equilíbrio dinâmico em diferentes pacientes neurológicos por meio do teste Get Up And Go. Rev Neurocienc. 2006;14(3):135-9.

22. Edwards DF, Hahn M, Baum C, Dromerick AW. The impact of mild stroke on meaningful activity and life satisfaction. J Stroke Cerebrovasc Dis. 2006;5(4):151-7. https://doi.org/10.1016/j.jstrokecerebrovasdis.2006.04.001

23. León-Carrión J, Machuca-Murga F, Murg- Sierra M, Domínguez-Morales R. Eficacia de un programa de tratamiento intensivo, integral y multidisciplinar de pacientes con traumatismo craneoencefálico: valores médico legales. Rev Neurol. 2001;33(4),377-83.

24. Lana R, Alvares L, Nasciutti-Prudente C, Goulart F, Teixeira-Salmela L, Cardoso F. Percepção da qualidade de vida de indivíduos com doença de Parkinson através do PDQ-39. Rev Bras Fisioter. 2007;11(5):397-402. https://doi.org/10.1590/S1413-35552007000500011 